\title{
A língua presa de Fidípides
}

Bruno Salviano Gripp

bruno.gripp@gmail.com

ABSTRACT: Pheidippides has been the most overseen character in Aristophanes' Clouds, even if the ultimate end to the comedy depends on him. He has been often thought by many commentators as a less interesting character than Socrates or Strepsiades. We attempt to interpret his character in terms of his characterization, origin and interests. As we can see from his dealings with horses and his association with Socrates, he bears a strong connection with the thoughts and activities of the higher class Athenian youth, and due to his high debts and his lisp we can attach him to Alcibiades, who seems to be an important model for this character. As it turns out, Pheidippides is an important mirror of Athenian high classes and the influence of Philosophers and Sophists alike on them.

KEYWORDS: Aristophanes; Clouds; Alcibiades; Socrates.

Temos mais informação acerca das últimas décadas do século $\mathrm{V}$ a.C. e das primeiras do IV do que de boa parte do resto da Antiguidade. O volume e a qualidade das fontes são capazes de nos fazer compreender este período como provavelmente nenhum outro na História Antiga. Tucídides, Xenofonte, Platão, Isócrates, o longo corpus de oradores, a Tragédia e os escólios que abundam para muitos destes escritores são fontes que nos dão informações inestimáveis a respeito do período. Isso talvez nos tenha permitido elucidar melhor a Comédia Antiga, tendo em vista que a comédia é o gênero literário que mais do que qualquer outro necessita de contextualização. Com efeito, a quantidade de referências veladas, que às vezes ficam escondidas pelas críticas mais evidentes, é suficiente para encher um longo comentário a cada uma das comédias.

Dentre essas comédias, vou-me ocupar d'As nuvens, produzida pela primeira vez no ano de 423 a.C., que coloca em cena uma personagem muito conhecida de Atenas, e, possivelmente, ainda mais conhecida da posteridade: Sócrates. Na comédia, o venerável filósofo aparece em roupagem totalmente diferentes daquelas presentes no longo corpus socraticum, em especial nos diálogos de Platão e Xenofonte. Ao contrário do nobre pregador da virtude, imagem tão consistente nos dois escritores, encontramos um sicofanta, interessado em conseguir dinheiro por meio do seu conhecimento e totalmente afastado do código moral padronizado da sociedade.

Naturalmente, pensa-se n'As nuvens como uma comédia filosófica, uma comédia cujo intento principal é escarnecer as tendências filosóficas em moda. Com efeito, ela é a única comédia, dentre as que nos restaram (e, possivelmente, dentre todas as outras há 
apenas duas outras exceções), ${ }^{1}$ que tem um filósofo como personagem central e a representar a atividade de figuras que hoje chamaríamos de filósofos ${ }^{2}$ como um elemento importante na trama. No caso d'As nuvens, não apenas a temática é singular, como a personagem escarnecida (para usar uma tradução ruim do original, $\kappa \omega \mu \omega \delta$ oú $\mu \varepsilon v o s$ é uma figura muito famosa e importante na história do pensamento grego.

A presença de Sócrates mostrou-se um ímã irresistível para toda a crítica posterior, e é praticamente impossível encontrar uma interpretação e leitura da obra que não toque, ainda que de forma marginal, na figura do filósofo e na sua relação com a personagem encontrada nas obras de Xenofonte e Platão. Na verdade, tal fixação pode ser vista desde a Antiguidade, pois todas as referências antigas à comédia de Aristófanes relatam algum fato relacionado a Sócrates. ${ }^{3}$ Nos tempos modernos, a questão socrática tornou-se uma das maiores razões pelas quais As nuvens é estudada, além de toda interpretação influente da comédia dedicar uma parte importante à caracterização dessa personagem.

No entanto, As nuvens não são somente uma comédia de temática filosófica, mas também englobam questões que ultrapassam, ou até mesmo obscurecem, qualquer questão doutrinal que seja levantada em cena. Foi preciso justamente um filósofo para colocar tais questões em relevo, pois, até onde temos notícia, Leo Strauss ${ }^{4}$ tornou-se o primeiro a destacar a crítica social da comédia.

A obra de Leo Strauss consagrada a Aristófanes é um profundo comentário da relação entre a poesia, em especial a comédia de Aristófanes, e a filosofia nascente, em especial o pensamento de Sócrates. Uma de suas considerações relata que a razão pela qual Aristófanes considera a filosofia perigosa está na crítica e na destruição que esta faz dos valores tradicionais da sociedade - segundo o filósofo americano, nisso não há

\footnotetext{
${ }^{1}$ Os Aduladores e As Cabras, de Êupolis, são as únicas comédias de cujo enredo temos conhecimento suficiente para termos ideia de que tratam de um assunto que poderíamos chamar de filosófico. Naturalmente, elas não são as únicas comédias a se referirem a conceitos, temas e doutrinas filosóficas, mas falta-nos completamente o contexto destas citações para podermos ter alguma ideia do assunto destas comédias.

${ }^{2}$ A terminologia é confusa e aberta à interpretação: não há terminologia específica para filósofo no século V: de acordo com Edmunds (What was Socrates Called? The Classical Quarterly. Chicago, vol. LVI, $\mathrm{n}$. 2, p. 414-442), o termo filósofo é uma criação de Platão. O próprio conceito de um filósofo com uma função própria e diferenciada de figuras como adivinhos, poetas e médicos não está bem estabelecido.

${ }^{3}$ Não são tantas as referências às Nuvens na tradição posterior; a rigor, apenas a referência velada, mas clara, na Apologia e uma citação mais tardia em Élio Aristides. Naturalmente, não considero comentários gramaticais e os escólios a Aristófanes.

${ }^{4}$ Cf. Strauss, L. Socrates and Aristophanes. Chicago: University of Chicago Press, 2001.
} 
diferença entre as figuras platônica e aristofânica de Sócrates. O exemplo em que mais se concentra Leo Strauss é o de Fidípides espancando o pai e a alusão ao incesto, presentes nas cenas finais da comédia.

O exemplo principal desta periculosidade de que fala Strauss podemos encontrar ao final d'As nuvens. A principal modificação na comédia, a peripécia, para utilizar a terminologia da tragédia, está no comportamento de Fidípides. Quem deixa isso muito claro é Estrepsíades, nos versos que se sucedem à segunda parábase da comédia:

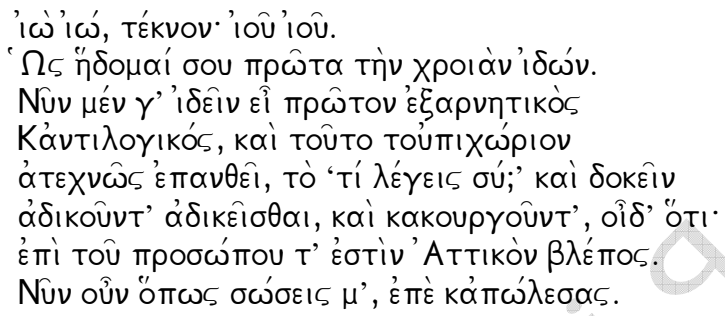

Estrepsíades fala claramente de duas mudanças, uma física e outra intelectual: na cor da pele e no comportamento. Aristófanes nunca faz uma distinção clara entre essas duas características. Desde o começo, os filósofos do Frontistério são caracterizados como tendo uma pele mais branca do que o comum, e este é o resultado natural dos estudos, a ponto de ficar pálido, ao fim da comédia, o próprio Fidípides. No entanto, o mais importante, e aquilo que o aspecto da pele apenas reflete, é a atitude em relação a disputas intelectuais e jurídicas. Agora Fidípides está plenamente apto a vencer qualquer disputa política, e Sócrates diz isso de forma bastante clara logo antes dessa passagem. ${ }^{5}$

As nuvens são uma comédia que focaliza de maneira igualmente importante a estranheza e o absurdo, tanto do pensamento das novas figuras intelectuais que vinham ganhando força na Atenas de fins do século $\mathrm{V}$, quanto da influência desses nos costumes e na juventude ateniense. Este último fato é representado especificamente pela figura de Fidípides. É a história central da comédia a transformação desse rapaz de um jovem desinteressado por qualquer atividade intelectual em um discípulo perfeito de Sócrates, completamente livre das amarras morais da sociedade.

\footnotetext{
${ }^{5}$ Esse verso de Sócrates é uma refutação àqueles que negam ver algum objetivo ilícito no filósofo: se isso não existisse, não haveria motivo para Sócrates expressar-se assim logo na volta de Fidípides, já que, pelo menos, ele está sendo conivente com os propósitos de Estrepsíades.
} 
O filho de Estrepsíades é caracterizado desde o seu nome como um apaixonado por cavalos, $\phi \varepsilon ı \delta-i \pi \pi-ı \delta \eta 5,{ }^{6}$ e a primeira entrada dele na comédia o mostra sonhando com presença em eventos hípicos. Como diz o pai, Fidípides importa-se com cavalos até dormindo. E são os gastos com esse entusiasmo que Fidípides tem com cavalos que causaram as dívidas das quais Estrepsíades quer fugir.

Relativamente pouca importância foi dada a esse fato, e as conexões e razões que o hipismo permite-nos fazer foram, em sua maior parte, ignoradas pelos comentadores da comédia. Porém, uma série de paralelos e relações podem facilmente ser feitos e ajudar-nos a explicar melhor alguns dos objetivos de Aristófanes com a comédia.

O primeiro dado é que as competições hípicas ${ }^{7}$ são, na Grécia, uma disciplina que se destaca das outras usualmente praticadas. ${ }^{8}$ Como todas as disciplinas esportivas, ela participa do ideário aristocrático arcaico, mas, ao contrário das outras, a pessoa que era celebrada como ganhador não era o auriga, quem participava do evento, mas o tratador dos cavalos. ${ }^{9}$ Esse fato já muda a ênfase do desempenho no evento para o tratamento dos animais, o que faz do hipismo uma disciplina que demanda menos exercício, treinamento e excelência física do atleta - ainda que historicamente ele se tenha mantido exclusivo da Aristocracia ${ }^{10}$ - do que gastos financeiros no tratamento e na compra de cavalos.

Para haver uma ideia das despesas que eram necessárias para o tratamento de cavalos, temos a informação, presente em Diodoro Sículo, ${ }^{11}$ de que Alcibíades teria gasto oito talentos na quadriga que lhe valeu a vitória em Olímpia. Se convertermos este valor para termos atuais, ${ }^{12}$ poderemos imaginar quanto esse valor representava. Tal

\footnotetext{
${ }^{6} \mathrm{O}$ processo de escolha do nome de Fidípides foi descrito por Estrepsíades na primeira cena da comédia. A mãe de Fidípides desejava um nome que tivesse a raiz de "cavalo", "i $\pi$ os em grego, enquanto

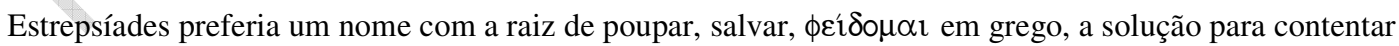

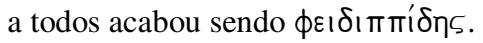

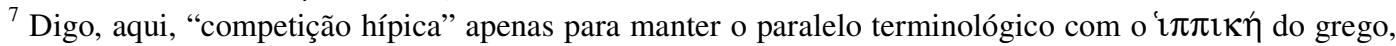
pois, formalmente, é algo mais próximo do que hoje chamamos de "turfe".

${ }^{8}$ Cf. Golden, M. Sport and society in ancient Greece. Cambridge: University Press, 1998, p. 169.

${ }^{9}$ Tal prática permanece até hoje no turfe, e gera discussões se se trata de um esporte ou não. Mas, para os gregos, isso nunca foi um problema.

${ }^{10}$ Cf. Golden, op. cit., p. 141.

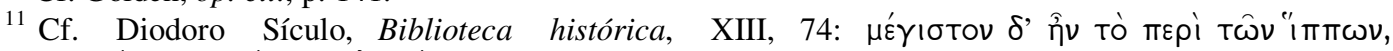

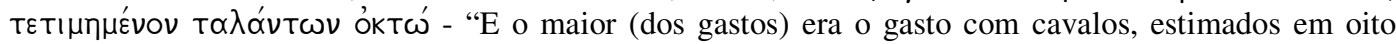
talentos" (minha tradução).

${ }^{12}$ Atividade meramente ilustrativa, já que a conversão de valores entre períodos históricos é praticamente impossível, quanto mais numa distância histórica tão grande.
} 
montante de oito talentos é equivalente a cerca de cento e trinta anos de trabalho de um trabalhador habilidoso, ${ }^{13}$ o que dá ideia do altíssimo valor despendido nesses jogos.

N'As nuvens, os valores que Estrepsíades deve a seus credores são condizentes com este montante. Logo no começo da comédia, Estrepsíades abre o seu livro de dívidas e se descobre devendo doze minas por causa da compra de um cavalo, três minas por um carro, um dinheiro a que, se imaginarmos as necessidades práticas da competição, deve ainda ser adicionado o valor de um ou três cavalos e o do sustento dos animais. Como seria de se esperar, não é um valor tão exorbitante quanto o de Alcibíades (e talvez revele algo sobre o exagero de nossas fontes!), mas trata-se de uma soma bastante considerável e proibitiva, exceto para a parcela mais rica da população.

Isso nos leva a um dos pontos centrais da presente discussão: as competições hípicas estavam tão associadas a classes mais abastadas que isso deve ter algum significado n'As nuvens. Fica difícil imaginar que Fidípides represente um tipo comum ou um tipo ideal da juventude grega, uma vez que os valores envolvidos na atividade que o caracteriza são representativos somente da parcela mais afluente da sociedade ateniense. Duas opções são possíveis: ou Fidípides está servindo como uma caricatura de um homem específico, ou sua situação é por si só ridícula, e alguém como ele, em tais jogos, seria completamente inadequado para a sociedade ateniense.

Fernandez, por exemplo, chega a dizer que Estrepsíades é uma representação das camadas mais baixas de Atenas; ${ }^{14}$ Estrepsíades estaria passando muito além de sua conta ao financiar os jogos do filho, e esta é a razão de sua falência. No entanto, há recursos para se acreditar que não é esse o caso de Fidípides em especial. Devemos fazer uma pequena genealogia da sua família para avaliar melhor esta situação.

De seu pai, Estrepsíades, sabemos apenas sobre sua origem rural, que ele nos deixa bem clara na primeira cena. Disso não se deve depreender a noção de que ele seja pobre ou menos provido por natureza. Dover atenta bem para esse ponto em sua

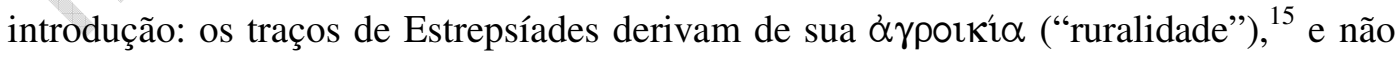
há absolutamente nada que nos possa fazer supor que ele seja de uma classe inferior à alta, com que normalmente temos contato na Comédia Antiga ou na literatura ateniense em geral. Na verdade, temos notícia do oposto. Estrepsíades tem um número

${ }^{13}$ Utilizamos os valores tradicionais estabelecidos por Cecil Torr em 1906 (Triremes. The Classical Review. Cambridge, vol. XX, p. 137, 1906): uma dracma por dia como salário, 100 dracmas por mina e 60 minas por talento; o total perfaz 48 mil dias ou, aproximadamente, 130 anos.

${ }^{14}$ Cf. Fernández, L. G. Aristófanes. Madrid: Gredos, 1996, p. 110.

${ }^{15}$ Cf. Dover, K. J. Aristophanic comedy. Los Angeles: University of California Press, 1972, p. 11. 
considerável de escravos, é literato, foi capaz de contrair grandes dívidas e casou-se com uma mulher de família influente. Não obstante as poucas informações que possuímos a respeito de sua fortuna, todas apontam mais para uma situação confortável do que para o contrário...

O maior indicativo da posição de Fidípides, porém, é a origem da sua mãe, e para isto temos de examinar de forma mais cuidada o monólogo de Estrepsíades:

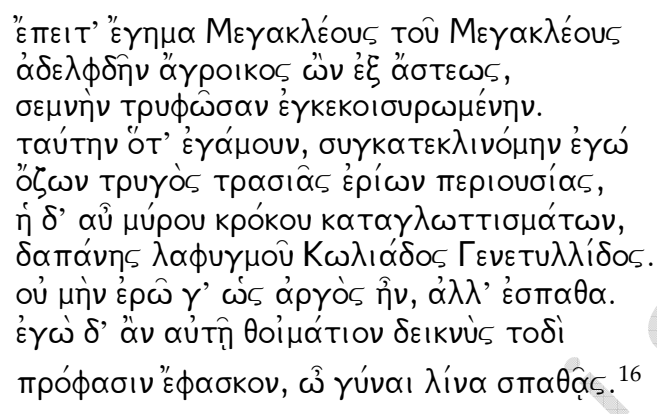

Essa passagem necessita de maiores explicações, pois utiliza uma série de referências culturais que não possuímos (infelizmente, os escoliastas também tinham dificuldades em estabelecer o significado desses nomes). A primeira encontra-se no primeiro verso: dizer que se casou com a sobrinha de Mégacles, filho de Mégacles, não significa apenas dizer que a mulher tinha parentes com um nome aparentemente aristocrático (grande glória), mas soava como referência específica a uma família ateniense, aquela dos Alcmeônidas.

Os Alcmeônidas são a família de maior importância e maior alcance na história de Atenas, e sua fama já estava bem assentada ainda antes da época de Aristófanes. ${ }^{17}$ Com efeito, Mégacles é um nome comum e muito importante nesta família. Encontramo-lo primeiramente num arconte do século VII, e o mesmo se repete pelo menos mais quatro vezes na linhagem até o quinto século (fato natural, dada a propensão dos nomes de avôs repetirem-se nas famílias). Um destes Mégacles tem

\footnotetext{
${ }^{16}$ Cf. As nuvens, v. 46-55: "Depois eu me casei com a sobrinha de Mégacles,/ filho de Mégacles, ela da cidade, sendo eu do campo./ Ela era respeitosa, refinada, toda como Cesira./ Quando casei-me com essa, e deitei-me com ela/ cheirando a uva, lã, fartura,/ ela, por seu turno, cheirava a mirra, açafrão, beijos de língua,/ dívida, gulodice, colíade e genetlíade./ Nem direi quão lerda era, mas ela gastava,/ e eu, mostrando-lhe este manto aqui,/ dizia: ó mulher, gastas demais" (minha tradução).

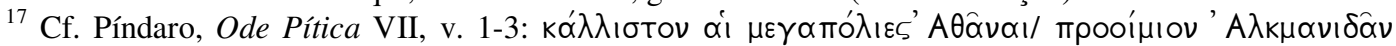

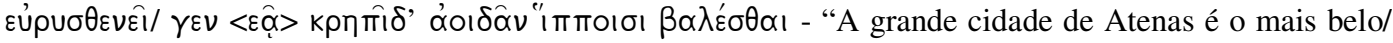
proêmio para lançar um canto elevado/ à poderosa raça dos Alcmeônidas por causa dos cavalos" - (minha tradução).
} 
relação direta com o tema da comédia: foi campeão nos jogos Píticos, e celebrado por Píndaro numa de suas Odes. ${ }^{18}$

Seria esse o "tio Mégacles" de que temos a referência no verso 46? Provavelmente não, pois a distância cronológica entre a comédia de Aristófanes impediria que a conexão entre estas personagens fosse facilmente compreendida pelo público. No entanto, isso serve apenas para estabelecer a relação que a família tinha com tais desportos. De fato, não apenas este Mégacles, mas vários outros membros da família conseguiram vitórias em jogos panelênicos, a grande maioria em competições de cavalos.

Outra possível correspondência a essa menção é haver um Mégacles, filho de Mégacles, que foi administrador dos fundos da cidade no ano de 429-428 a.C., e que poderia, talvez, ser filho deste Mégacles da ode de Píndaro. ${ }^{19}$ Aristófanes já fizera referência anterior a ele, nos Acarnenses. ${ }^{20}$

Não se trata de uma citação ociosa, porque reaparece novamente na comédia em mais três ocasiões: quando o pai relata uma conversa de sua mulher com o filho, ${ }^{21}$ quando Fidípides avisa o pai de que seu tio Mégacles não vai deixá-lo sem cavalos $^{22}$ e volta a ser lembrado, mais ao final da comédia, quando percebe-se que ele vai precisar de Fidípides para escapar de suas dívidas. ${ }^{23}$ As três referências são importantes porque demonstram que a relação de Fidípides com a família dos Alcmeônidas não é apenas uma citação “ornamental”, mas, pelo contrário é mantida coerentemente ao longo da trama.

A relação com a família dos Alcmeônidas continua em v. 46: com a citação do

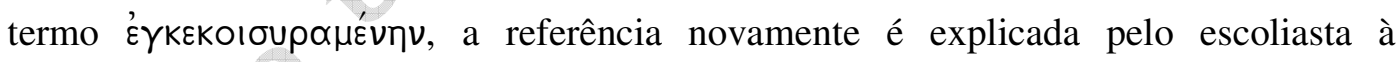
passagem $^{24}$ como sendo a uma personagem chamada Cesira, da Eritreia, mãe de um dos

\footnotetext{
${ }^{18}$ Cf. Píndaro, Ode pítica VII.

${ }^{19}$ Cf. Shear, L. Koisyra: three women of Athens. Phoenix. Toronto, vol. XVII, n. 2, p. 99-112, 1963, p. 102, diz corretamente, a nosso ver, que as referências aos dois Mégacles nascidos no final do século VI são demasiado distantes para serem críveis. Ele supõe que este Mégacles filho de Mégacles seja filho de um desses dois Mégacles e, portanto, um Alcmeônida. Não há base textual segura, mas a existência de um Mégacles filho de Mégacles nos arquivos da Ágora e a quase inexistência desse nome, em Atenas, fora da família, induzem a crer que esse seja mesmo o caso.

${ }^{20}$ Cf. Shear, op. cit., p. 100.

${ }^{21}$ Cf. As nuvens, v. 70.

${ }^{22}$ Cf. As nuvens, v. 124.

${ }^{23}$ Cf. As nuvens, v. 814.

${ }^{24}$ Cf. Anônimo. Prolegomena de comoedia. Scholia in Acharnenses, Equites, Nubes. Groningen: Bouma, 1977.
} 
Mégacles, ${ }^{25}$ algum dos vários da família dos Alcmeônidas. Essa Cesira seria mulher muito dada ao luxo e à dissipação da riqueza, e tal seria o motivo para referi-la. De novo, isso não vai ser irrelevante, porque reaparecerá em outro momento da comédia:

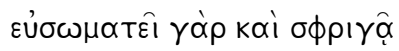

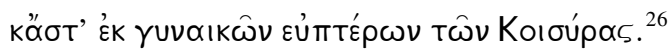

Com esses comentários, podemos ver que Aristófanes compõe ao longo da comédia um quadro coerente da relação entre Fidípides e membros da família dos Alcmeônidas. São muitas as referências, elas se repetem de maneira coerente e parecem ser um motivo importante na comédia. Isso não pode ser irrelevante, e certamente há um motivo por detrás delas. Podemos divisar duas soluções, que não são mutuamente excludentes: a primeira é que, ao valer-se de uma família importante e famosa (como disse mesmo Heródoto, ${ }^{27}$ sobre a relevância de seus membros - Clístenes, Péricles, etc.), Aristófanes emprega a fama e a influência de um clã importante para fixar um comportamento característico da camada ateniense rica. Neste sentido, Fidípides seria apenas um representante característico dos interesses e influências da camada mais alta e influente da vida ateniense.

Se pensarmos na comédia como um todo e em sua significação mais geral, essas considerações possuem alguma coerência. Fidípides poderia representar a influência que as figuras de status semelhante ao seu começavam a ter sobre homens da mais alta sociedade ateniense. Poder-se-ia lembrar, por exemplo, das relações entre Protágoras e Péricles, além do sucesso que Górgias obteve em suas passagens por Atenas. ${ }^{28}$

No entanto, podemos obter referências ainda mais precisas em relação à personagem de Fidípides. Pois há uma figura histórica que compartilha muitas semelhanças com o Fidípides da comédia, e estamos falando de uma personagem muito famosa, que é Alcibíades. Alcibíades, tal qual Fidípides, pertencia à família dos

\footnotetext{
${ }^{25}$ Apesar da segurança da referência, ainda há muita incerteza em relação aos detalhes das pessoas que chamamos de "Cesira”. Há uma série de reconstruções da família (cf. Shear, op. cit., 1968 p. 103), mas não é preciso seguir nenhuma delas para o presente trabalho.

${ }^{26}$ Cf. As nuvens, v. 799-800: "Ele é robusto e saudável,/ e vem das mulheres de belas plumas de Cesira" (minha tradução).

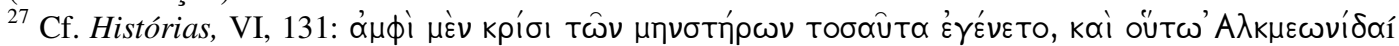

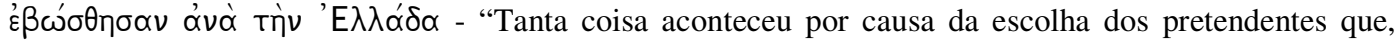
assim, a fama dos Alcmeônidas ressoou por toda a Grécia" (minha tradução).

${ }^{28}$ Cf. Guthrie, W. K. C. Socrates. Cambridge: University Press, 1995, p. 244.
} 
Alcmeônidas por parte de mãe $\mathrm{e}^{29}$ e, como Fidípides, era parente próximo (sobrinho) de Mégacles, filho de Mégacles. Pouco sabemos da carreira e da vida do pai de Alcibíades, Clínias, exceto a informação de que ele morreu na batalha de Coroneia. ${ }^{30}$

Além das conexões familiares, a proximidade entre o comportamento de Fidípides e o de Alcibíades é bastante evidente. A relação entre Alcibíades e Sócrates é uma das relações mais bem documentadas da Antiguidade: além das extensas passagens em Platão e Xenofonte, ${ }^{31}$ somos informados por Plutarco e outras fontes da existência de obras sobre Alcibíades escrita por socráticos como Antístenes e Fédon. Alcibíades é o grande calcanhar de Aquiles da vida de Sócrates; sua fama e as consequências de suas ações foram usadas desde, talvez, a vida do filósofo como motivo de acusações e críticas. $^{32}$

O significado que a figura de Alcibíades assume nessa literatura, entretanto, não pode ser comparado com o significado que Alcibíades tinha na época da composição d'As nuvens. Naquele tempo, Alcibíades ainda estava longe de ser um homem contraditório, e mais longe ainda de significar a ruína da cidade. Naquele momento, Alcibíades pouco passava de um jovem aspirante a general, de família influente e personalidade extravagante.

Uma das maiores extravagâncias desse jovem Alcibíades era o seu amor pelos jogos hípicos: famosa foi a sua participação nos jogos Olímpicos de 416, quando terminou em primeiro, segundo e quarto na quadriga. Como nos informa a fonte mais próxima, Tucídides, citando um provável discurso de Alcibíades,

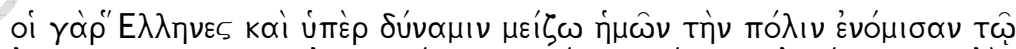

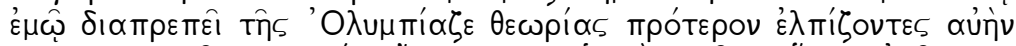

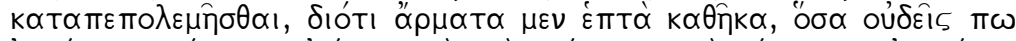

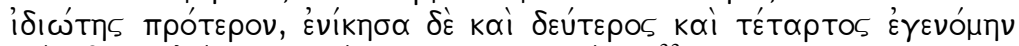

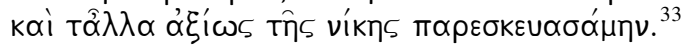

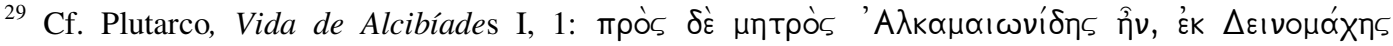

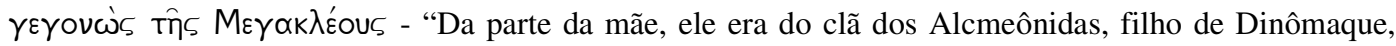
filha de Mégacles" (minha tradução).

${ }^{30}$ Cf. Plutarco, Vida de Alcibíades I 1.

${ }^{31}$ Cf. Banquete, Protágoras e os dois Alcibíades, possivelmente espúrios.

${ }^{32} \mathrm{Cf}$. Gribble, D. Alcibiades and Athens. A study in literary presentation. New York: Oxford University Press, 1999, p. 190.

${ }^{33}$ Cf. Tucídides, História da guerra do Peloponeso, VI 16: "Os gregos, com efeito, antes esperavam que nossa cidade tivesse sido destruída pela guerra, mas por causa da minha distinção na apresentação em Olímpia, julgaram-na mais poderosa do que ela é, isso tudo porque eu inscrevi sete carros, uma quantidade que nenhum particular tinha inscrito antes. E venci, fui segundo e quarto, e ainda preparei as outras de maneira digna para a vitória" (minha tradução). 
Plutarco mesmo chega a citar uma ode triunfal composta por Eurípides, escritor sobre o qual Fidípides diz ser o melhor dos poetas. ${ }^{34} \mathrm{Nem}$ tudo, porém, era tão grandioso como Alcibíades (ou, ao menos, o Alcibíades de Tucídides) queria demonstrar, pois, pouco antes desse discurso, Tucídides nos informa que Alcibíades se endividava imensamente com as despesas desses jogos:

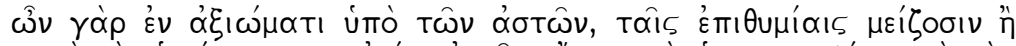

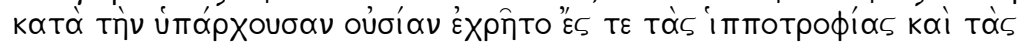

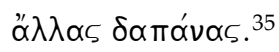

Tendo em vista os valores mencionados acima, não é de causar espanto que Alcibíades tenha-se endividado além da sua riqueza com esse divertimento.

A proximidade com a personalidade de Fidípides, pelo que até agora foi dito, é bastante evidente: ambos são descendentes, por parte de mãe, dos Alcmeônidas, ambos se tornam discípulos de Sócrates, e ambos têm como diversão principal os jogos hípicos, nos quais dissipam toda a fortuna da família. Com tudo isso em vista, considero que tal paralelismo não pode ter passado em branco à primeira audiência, e que Aristófanes queria, mesmo, colocar em cena uma referência, ainda que velada, a Alcibíades.

Mas há ainda uma referência ulterior a outra característica, dessa vez física, relevante de Alcibíades, como é comentado primeiramente por Aristófanes:

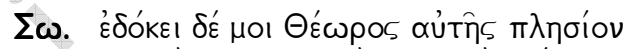

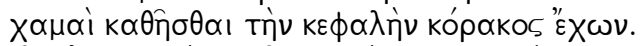

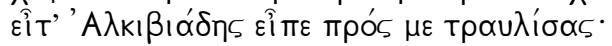

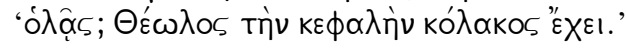

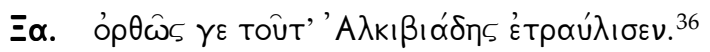

E, segundo nos é, depois, confirmado por Plutarco, Alcibíades tinha um problema de sigmatismo; ${ }^{37}$ Estrepsíades, por sua vez, refere-se a Fidípides como também tendo esta característica desde a infância:

\footnotetext{
${ }^{34}$ Cf. As nuvens, v. 1377.

${ }^{35}$ Cf. Tucídides, História da guerra do Peloponeso, VI 15: "Pois por ter a distinção que tinha entre os cidadãos, tinha desejos maiores do que a fortuna lhe permitia em cuidados com cavalos e outras despesas" (minha tradução).

${ }^{36}$ Cf. As vespas, v. 42-45: "Sósias: E parecia-me que Teoro, perto dela,/ assenta-se no chão com a cabeça de um corvo,/ e Alcibíades fala comigo com a sua língua presa:/ "veja, Teolo tem a cabeça de um adulador'./ Xântias: E língua presa de Alcibíades falou certo” (minha tradução).

${ }^{37}$ Conhecido popularmente como "língua presa".
} 


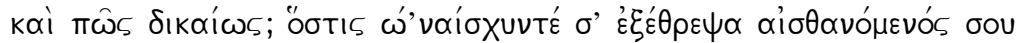

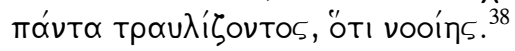

Cremos que, depois de tantas "referências veladas" a Alcibíades ao longo de

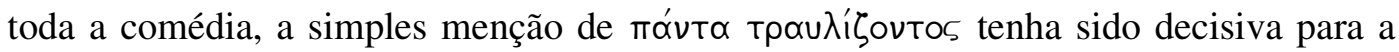
plateia. Fidípides carregava muito de Alcibíades e, talvez, até a plateia tenha rido neste momento. Porém, Aristófanes não afirma de forma aberta essas particularidades de Alcibíades, e não quis colocá-lo sob o próprio nome. A partir disso, pode-se questionar a razão pela qual Aristófanes não colocou o mesmo Alcibíades em cena e fez dele mais um $\kappa \omega \mu \omega \delta$ oú $\mu \varepsilon v o s$ na comédia, como o são, nela, Sócrates e Querefonte.

Temos ao menos dois motivos para isso: o primeiro é que, no momento em que As nuvens foram escritas, Alcibíades já havia ultrapassado em muito a idade de

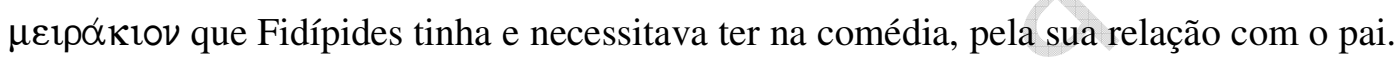
Se analisarmos a cronologia da vida de Alcibíades, ele já devia estar próximo dos trinta anos no momento da primeira versão d'As nuvens, e mostrá-lo como filho de Estrepsíades, sem responsabilidade pela casa, seria bastante inverossímil.

Nesse ponto, é importante lembrar que, antes de em qualquer relação com figuras históricas, As nuvens centram-se numa característica básica de toda comédia: a relação entre pais e filhos. Aristófanes, aqui, segue um padrão provavelmente já estabelecido na comédia entre um pai envelhecido e um filho fascinado por novidades nocivas. Divisamos esse padrão em comédias perdidas, mas de cujo argumento podemos ter uma vaga ideia, como As cabras, de Êupolis, e Os convivas, de Aristófanes. ${ }^{39}$ As cabras, em especial, aproximam-se muito d'As nuvens em termos de semelhança da trama, e mesmo, há quem comente, de uma influência sobre elas. A comédia não é uma comédia sobre Alcibíades, mas sobre a relação entre pais e filhos. ${ }^{40}$

Outro ponto importante é que, por mais que a caricatura de Alcibíades seja perceptível, ela não se resume à sua personagem histórica, pois também refletia a atitude de uma série de outros jovens que, como ele, vinham de famílias influentes e se aproximaram de figuras como Sócrates. Existem outros exemplos de discípulos de Sócrates, tais como Crítias e Platão. Além deles, Cálias, filho de Hipônico, também era

\footnotetext{
${ }^{38}$ Cf. As nuvens, v. 862: "E como justamente? Quem, ó sem vergonha, te criei,/ ouvindo-te falar com a língua presa tudo que pensavas" (minha tradução).

${ }^{39}$ Cf. Storey, I. C. Eupolis, a poet of ancient comedy. New York: Oxford University Press, 2004, p. 131, e Fernández, op. cit., p. 150.

${ }^{40}$ Isso serve para refutar a afirmação de Vickers, que veremos mais adiante.
} 
bastante afinado com homens como Protágoras e Pródico, sendo esse último uma dos personagens centrais de uma comédia de temática parecida à d'As nuvens: Os aduladores, de Êupolis. Aristófanes provavelmente evitou fazer uma crítica específica a Alcibíades e preferiu fazer de Fidípides uma caricatura de todo um grupo social que se estava aproximando e sendo influenciado cada vez mais por personagens filosóficas e/ ou sofísticas.

Essa teoria não é de todo nova, a primeira referência a ela encontra-se em um dos primeiros (se não o primeiro!) comentários às Nuvens. Süvern, ${ }^{41}$ em 1812, fez uma primeira aproximação de Fidípides com Alcibíades. O estudioso alemão nota certas proximidades entre as duas figuras: o interesse por cavalos, a origem aristocrática e o sigmatismo. No entanto, o ponto central de sua análise está em enxergar a relativa dissipação moral das duas figuras. Embora essa seja uma característica presente em ambos, é difícil encontrar um paralelo exato entre as duas personagens, sendo que, na verdade, o comportamento de Fidípides, ao final da comédia, é uma característica básica do gênero. Filocléon, o Salsicheiro, e muitos outros, para mencionar um exemplo, terminam as comédias com um comportamento semelhante.

Depois de Süvern, essa aproximação ficou esquecida por muitos anos até retornar, em 1997, num livro de Vickers, ${ }^{42}$ em que se tenta argumentar que, nas primeiras comédias, há a unidade temática da sátira a Péricles. As nuvens tentariam colocar em cena a relação entre Péricles, representado por Estrepsíades, e Alcibíades, representado por Fidípides. O livro foi recebido de forma muito crítica, ${ }^{43}$ e muitas das atribuições são bastante inverossímeis. No entanto, a atribuição da referência a Fidípides foi considerada plausível.

O argumento de Vickers é de que As nuvens são uma parábola política da ligação entre Alcibíades e Péricles, e da maneira com que ambos tratam a guerra e a administração da "Polis". Os argumentos que Vickers faz para aproximar Péricles de Estrepsíades são, porém, bem mais fracos do que os de Fidípides: Estrepsíades faria diversos comentários concernentes à morte, ambos são parcimoniosos e Estrepsíades

\footnotetext{
${ }^{41}$ Cf. Süvern, J. W. Two essays on “The clouds" and the “Г̄̄pos" of Aristophanes. Londres: John Murray, 1836, p. 41.

${ }^{42}$ Cf. Vickers, M. Pericles on stage. Political comedy in Aristophanes' early plays. Austin: University of Texas Press, 1997, p. 45.

${ }^{43}$ Cf. as resenhas: Sidwel, K.: Aristophanic allegory. The Classical Review. Cambridge, vol. XLVII, n. 2, p. 254-255, 1997, e Hubbard, T. Pericles on Stage. Classical philology. Chicago, vol. 93, n. 4, p. 370-375, 1998.
} 
tem problemas de memória, o que é considerado, por Tucídides, um dos sintomas da peste que vitimou Péricles.

A diferença da nossa leitura com relação à desses dois predecessores está na interpretação dos fatos. Evitamos citar os dois na argumentação central por ambos seguirem uma linha de raciocínio completamente diferente (e independente) da argumentação presente no nosso texto. E ambos apresentam fragilidades, a nosso ver, num ponto importante, o da interpretação dos nomes a aparecerem no início da comédia. Ambos tendem a imaginar um parentesco com Mégacles, campeão olímpico em 486 e o primeiro a ser banido por ostracismo. Tendemos a crer que essa figura está muito distante da época de Aristófanes para ser uma referência clara e compreensível para o público em geral. Quanto a isso, a existência de um Mégacles, filho desse Mégacles, como é suposta por Shear, ${ }^{44}$ torna a atribuição mais precisa e mais clara. Com ela, podemos também afastar-nos da tradicional interpretação de um nome abstrato, que apenas aludia a uma certa Aristocracia.

Ambos também citam o amor por cavalos que é, evidentemente, um fator importante na caracterização de Fidípides, embora não a informação de Tucídides de que o próprio Alcibíades gastava dinheiro além da conta com essas suas diversões. Cremos que tal fato torna ainda mais verossímil a apresentação entre os dois, especialmente se pensarmos que Alcibíades pode ter sido ele mesmo vítima da perseguição de algum credor.

Süvern prefere ver apenas, como nós, uma sutil alusão a Alcibíades, ${ }^{45}$ mas Vickers vê isso tudo como fazendo parte de um tema comum das comédias de Aristófanes contra Péricles e Alcibíades. Tal teoria foi rejeitada unanimemente, faltanos em absoluto qualquer evidência histórica que a prove. Qualquer tentativa de divisar uma parábola política parece fadada ao fracasso, e significa politizar em excesso um gênero que não é exclusivamente político. Além disso, Aristófanes não é um alegorista a esconder-se por referências vagas e escrevendo comédias com significados obscuros. Isso nos parece, mesmo, um propósito contrário à própria ideia de "drama público", como é o teatro ateniense. Qualquer referência possível a Péricles é muito sutil para ser

\footnotetext{
${ }^{44}$ Cf. Shear, op. cit., p. 115.

45 Süvern também propõe, baseando-se no segundo argumento à comédia, que Alcibíades teria sido o culpado pelo insucesso da mesma (op. cit., p. 33). Apesar de constituir um dado sedutor, é preciso ter em conta que todo o segundo argumento não é uma fonte muito confiável: ele também afirma que Anito e Meleto, os acusadores de Sócrates, eram responsáveis pela comissão da comédia. Uma afirmação absurda, tanto mais se considerarmos que Anito pouco era mais do que um bebê no ano de 423 a.C.
} 
compreendida pelo público, além de sua ligação com Sócrates ser, no mínimo, frágil. A figura de Alcibíades, porém, é historicamente importante para a vida de Sócrates, acreditando-se até em que ele chegou a ser citado no discurso de acusação do filósofo. Seus atos causaram um certo constrangimento, a ponto de Xenofonte ${ }^{46}$ tentar desculparse de todo modo do legado de Alcibíades e de sua proximidade com Sócrates; mas seu relacionamento é concreto e importante para a biografia dos dois homens.

Mais importante do que isso, e retomando a questão inicial, é que As nuvens se revelam, com essa referência a Alcibíades, uma comédia social: analisam e criticam o papel que Sócrates possuía na "educação" de Alcibíades e dos outros jovens de famílias abastadas que frequentavam seu círculo. Curiosamente, para Aristófanes, a eficiência do treinamento de Sócrates é total: ele transforma um jovem completamente desinteressado por outro assunto diferente dos cavalos num perfeito sofista. Xenofonte se serve justamente do argumento oposto: Alcibíades não seguiu à risca os conselhos de Sócrates.

A acusação de Aristófanes não se revela tão grave quanto os eventos futuros de Atenas. Até então, Alcibíades devia ser visto apenas como um jovem de família rica, com hábitos extravagantes e que estava começando a sua carreira política; todos os eventos citados na História de Tucídides, e em outras obras que tratam de Alcibíades, acontecem depois da produção d'As nuvens. Que a carreira deste jovem, que se relacionava com outra personagem bastante inusitada, Sócrates, tenha vindo a terminar em tragédia para a cidade, era algo completamente fora do alcance de qualquer dos envolvidos.

A filosofia, no quinto século, ainda se mostrava como prática estranha, marginal e temida na sociedade grega... Porém, é justamente a geração de Sócrates que leva a filosofia, pela primeira vez, a foro público, especialmente seus famosos alunos e discípulos, todos influentes na política como Alcibíades. As nuvens são um testemunho raro deste evento, quando a filosofia se torna, pela primeira vez, um fenômeno sociológico, pela pervasiva influência numa certa camada social e pelos efeitos que ela teve na condução histórica da cidade e das vidas dos cidadãos. É difícil imaginar um outro período da história em que isso também tenha ocorrido, e esse é um dos motivos para não termos refacções d'As nuvens.

\footnotetext{
${ }^{46}$ Cf. Gribble, op. cit., p. 175.
} 


\section{Referências}

ANÔNIMO. Prolegomena de comoedia. Scholia in Acharnenses, Equites, Nubes. Groningen: Bouma, 1977.

ARISTOPHANE. Comédies. Les Acharniens. Les cavaliers. Les nuées. Paris: Les Belles Lettres, 2002.

Aristophanis comoediae. Acharnense. Equites. Nubes. Vespas. Pacem. Aves continens. Oxford: Clarendon Press, 1966. Tome I.

CLAUDIVS AELIANVS. Claudii Aeliani de natura animalium libri XVII. Varia Historia. Epistolae. Fragmenta. Leipzig: Teubner, 1966. Vol. II.

DOVER, K. J. Aristophanic comedy. Los Angeles: University of California Press, 1972. . Aristophanes' clouds. London: Oxford University Press, 1967.

EDMUNDS, L. What was Socrates Called?. The Classical Quarterly. Chicago, vol. LVI, n. 2, p. 414-442, 2006.

FERNÁNDEZ, L. G. Aristófanes. Madrid: Gredos, 1996.

GOLDEN, M. Sport and society in ancient Greece. Cambridge: University Press, 1998.

GRIBBLE, D. Alcibiades and Athens. A study in literary presentation. New York: Oxford University Press, 1999.

HUBBARD, T. Pericles on Stage. Classical philology. Chicago, vol. 93, n. 4, p. 370$375,1998$.

KOCK, T. Comicorum Atticorum fragmenta. Comoedia antica. Leipzig: Teubner, 1880. Vol. I.

LÉVY, E. La Grèce au Ve. siècle. Paris: Du Seil, 1995.

NORWOOD, G. Greek comedy. London: Methuen and Co., 1961. 


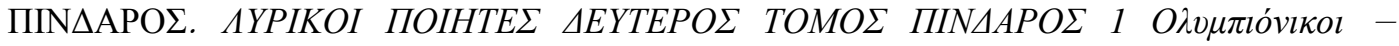

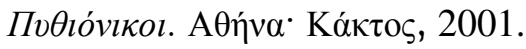

PLATO. Platonis Opera. Theages. Charmides. Laches. Lysis. Euthydemus. Protágoras. Gorgias. Meno. Hippias Maior. Hippias Minor. Io. Menexenus recognouerit J. Burnet. Oxford: Clarendon Press, 1968. Vol. III.

PLUTARCO. Plutarchi uitae parallelae. Leipzig: Teubner, 1964. Vol. I-II.

SHEAR, L. Koisyra: three women of Athens. Phoenix. Toronto, vol. 17, n. 2, p. 99-112, 1963.

SIDWELL, K. Aristophanic allegory. The Classical Review. Cambridge, vol. XLVII, n. 2, p. 254-255, 1997.

STOREY, I. C. Eupolis, a poet of ancient comedy. New York: Oxford University Press, 2004.

STRAUSS, L. Socrates and Aristophanes. Chicago: University of Chicago Press, 2001.

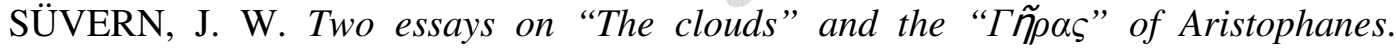
London: John Murray, 1836.

TORR, C. Triremes. The Classical Review. Cambridge, vol. XX, p. 137, 1906.

TUCÍDIDES. Thucydidis historiae. Oxford: Clarendon Press/ Oxford University Press 1970. Vol. II.

VICKERS, M. Pericles on stage. Political comedy in Aristophanes' early plays. Austin: University of Texas Press, 1997.

XENOPHON. Xenophontis opera omnia. Libri socratici recognouerit E. C. Marchant. Oxford: Clarendon Press/ Oxford University Press, 1971. 